\title{
LXII. Inquiry respecting a correction requisite in the working of Dr. Olbers's method of determining the elements of the orbits of comets
}

\section{R. Templeton Esq.}

To cite this article: R. Templeton Esq. (1842) LXII. Inquiry respecting a correction requisite in the working of Dr. Olbers's method of determining the elements of the orbits of comets, Philosophical Magazine Series 3, 20:132, 411-411, DOI: 10.1080/14786444208650599

To link to this article: http://dx.doi.org/10.1080/14786444208650599

曲 Published online: 01 Jun 2009.

Submit your article to this journal $[\pi$

Џll Article views: 2

Q View related articles $\sqsubset$ 
of Fernel, and a supposed result so near the truth, it was not difficult to attribute to hazard the success of another operation of a somewhat similar kind. But those who attend to the subject, and whom I am able to convince that Fernel's result was on the wrong side of 54 miles, instead of the right side of 69 , will perhaps take another look at the mode pursued by Norwood, in which case I am inclined to think they will be able to satisfy themselves, that instead of rowing in the same boat as Fernel, with luck for the steersman, he is well entitled to have his conclusion considered as the result of such skill and patience as could not have led to any other.

I remain, Gentlemen, yours faithfully,

University College, April 2, 1842.

A. De Morgan.

LXII. Inquiry respecting a correction requisite in the roorking of Dr. Olbers's method of determining the Elements of the Orbits of Comets. By R. Templeton, Esq.

To the Editors of the Philosophical Magazine and Journal.

\section{Gentremen,}

HAVING read over with much interest the method of determining the elements of the orbits of comets by Dr. Olbers in the last volume of your Magazine for 1835, I selected from Lieut. Stratford's Ephemeris of Halley's three positions, intending to familiarize myself with the practical working of the method, but a difficulty met me at the onset. It will be remembered that this comet was detected early in August, when its distance was about twice the radius of the earth's orbit; observations were afterwards made when it was only one-eighth of this quantity, and again when it had nearly acquired the same amount. Now in combining these observations, the omission of an allowance for the time elapsed since the comet had actually the positions observed, would introduce an error of a quarter of a minute in right ascension, and of half this in declination, which, however small or modified by errors of observation, ought not to be neglected; I wish in consequence to be informed by some of your Correspondents through the medium of your valuable Jounnal, whether it has been usual to apply a correction $-8^{\mathrm{m} \cdot 125} p$ to the time of observation after the first approximation admits of tolerably accurate values of the curtate distances being obtained.

I remain, Gentlemen, yours \&c.

Colombo, Jan. 26, 1842.

R. TEMPLEToN. 